\title{
Zambia's Energy Consumption and Related Carbon Emissions
}

\author{
Rejoice Mwamba a , b, Ru Guo ${ }^{\text {c }}$, , Simon Garang Kuch a , b \\ ${ }^{a}$ College of Environmental Science and Engineering, Tongji University, Shanghai, China \\ ${ }^{b}$ UNEP-Tongii Institute of Environment for Sustainable Development, Tongji University, Shanghai, China \\ ${ }^{\mathrm{c}}$ Institute of Environmental Planning and Management, College of Environmental Science and Engineering, Tongji University, Shan ghai, China \\ ${ }^{\mathrm{d}}$ Shanghai Institute of Pollution Control and Ecological Security, Shanghai, China
}

DOI: 10.29322/IJSRP.10.03.2020.p9938

http://dx.doi.org/10.29322/IJSRP.10.03.2020.p9938

\begin{abstract}
Clean safe and affordable energy is a necessity for every human being. Electricity, as an important modern energy, is a basic substance not only for national but individual and household development. In Zambia, only 40 percent of a population of about 17 million has access to electricity consisting of 67 and 4 percent urban and rural area access respectively. Since 1970 Zambia's electricity generation has largely been solely on the southerly located part of Zambezi as a major hydro power source. This predominant single energy electricity structure lead to high potential of social and economic risks. Lack of diversification and/or investments has left the majority of households relying on wood fuel and charcoal. And the process of traditional biofuel production and consumption are responsible for some energy-related carbon emissions. The growing population has outpaced the existing energy infrastructure which has resulted in long durations of service interruption. As a result of persistent annual electricity service disruptions only recently is energy mixing with solar, wind and others are being considered. Other than the already identified energy mixing, we further suggest, policy reforms that not only promote but also facilitate energy efficiency, public private partnerships with both indigenous and foreign private sector partners and technology transfer through schemes such as green technology bank.
\end{abstract}

Key Words- Carbon emissions, Electricity, Energy consumption, Hydroelectric Power (Hep), Urban and rural area.

\section{INTRODUCTION}

$\mathrm{G}$ lobally, diverse energy forms exist and are used at various geographical scales; national and local level with the smallest unit being the village (rural area). The energy includes coal, hydroelectric power, oils, biofuels, natural gas and biomass.

After three flat years, global energy-related carbon dioxide $(\mathrm{CO} 2)$ emissions rose by $1.6 \%$ in 2017 and the early data suggest continued growth in 2018, far from a trajectory consistent with climate goals [1]. Energy-related air pollution continues to result in millions of premature deaths each year. In recent times the world has seen a decrease in fossil fuel use with exceptions of China and the USA while generally, the use of renewable energy has increased. Carbon emissions are those stemming from the burning of fossil fuels and the manufacture of cement. They include carbon dioxide produced at some point in the consumption of solid, liquid, and gasoline fuels and gas flaring. Carbon dioxide $(\mathrm{CO} 2)$ is a naturally occurring gas fixed through photosynthesis into organic matter. A byproduct of fossil fuel combustion and biomass burning, it is additionally emitted from land-use modifications and other industrial processes. It is the primary anthropogenic greenhouse gas that influences the Earth's radiative balance. It is the reference gas against which other greenhouse gases are measured and makes up the largest share of the greenhouse gases contributing to global warming and climate change [2,3].

At the global scale, the key greenhouse gases emitted through human activities relating to energy production and consumption are Carbon dioxide (CO2), Methane (CH4), Nitrous oxide (N2O) and Fluorinated gases (F-gases). Fossil fuel use is the primary source of $\mathrm{CO} 2 . \mathrm{CO} 2$ can also be emitted from direct human-induced impacts on forestry and other land use, such as through deforestation, land clearing for agriculture, and degradation of soils. Likewise, land can also remove $\mathrm{CO} 2$ from the atmosphere through reforestation, improvement of soils, and other activities. $[4,5]$.

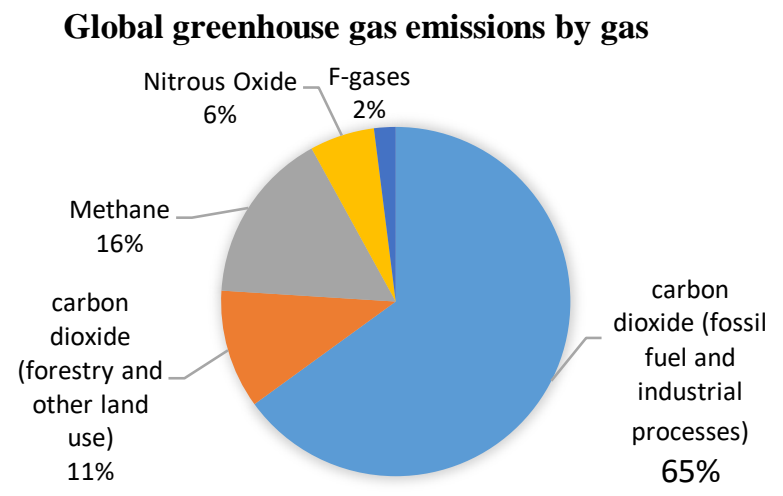

Figure 1: Global greenhouse gas emissions by gas Source: Adapted from [5]

Various sectors of the economy are responsible for several emissions at global level. Among these economic sectors include, electricity and heat production, industry, agriculture, forestry, and other land use, buildings and other energy. According to EPA [5] Electricity and Heat Production through the burning of coal, natural gas, and oil for electricity and heat is the largest single source of global greenhouse gas (GHG) emissions. For instance, 
$25 \%$ of 2010 global greenhouse gas emissions were electricity and heat production related. Industry is another sector that emits large amounts of GHG after electricity and heat production. Greenhouse gas emissions from industries mainly involve fossil fuels burned on-site at services for energy. Other emissions come from chemical, metallurgical, and mineral transformation techniques not associated with electricity consumption and emissions from waste management activities. Transportation emissions come from fossil fuels burned for road, rail, air, and marine transportation. And almost all (95\%) of the world's transportation energy comes from petroleum-based fuels, largely gasoline and diesel. Buildings emissions from this sector mainly arise from onsite energy generation and burning fuels for heat in buildings or cooking in homes.

Agriculture, Forestry, and Other Land Use Greenhouse gas emissions from this sector come mostly from agriculture (cultivation of crops and livestock) and deforestation. This estimate does not include the $\mathrm{CO} 2$ that ecosystems remove from the atmosphere by sequestering carbon in biomass, dead organic matter, and soils, which offset approximately $20 \%$ of emissions from this sector [6].

\section{Global greenhouse gas emissions by economic} sector

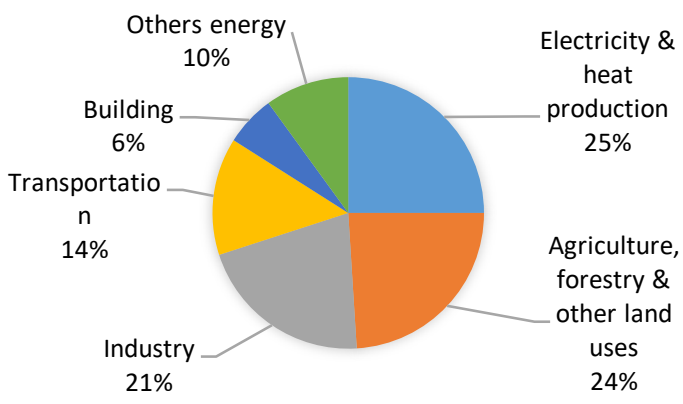

Figure 2: Global greenhouse gas emissions by economic sector Source: Adapted from [5]

In 2018, Africa accounted for around 4\% of the world's energy-related carbon dioxide $\left(\mathrm{CO}_{2}\right)$ emissions despite being home to around $17 \%$ of the population. The power sector was the largest emitting sector $\left(480 \mathrm{Mt} \mathrm{CO}_{2}\right)$ followed by transport (355 $\left.\mathrm{Mt} \mathrm{CO}_{2}\right)$ and industry $\left(150 \mathrm{Mt} \mathrm{CO}_{2}\right)$ [7]. The world atlas on environment [8] identifies Zambia along with other developing countries as been involved in unsustainable charcoal production practices. This because the practice triggers deforestation. Carbon a product of deforestation and/or charcoal production lies in the family of greenhouse gases which as well-known are contributors to global warming.

Figure 3 shows that global carbon emissions from fossil fuels have significantly increased since 1900 . And that from 1970, the emissions had increased by about $90 \%$, this can be attributed to emissions from fossil fuel combustion, industrial processes, agriculture, deforestation, and other land-use changes. This rising trend saw a tremendous increase between 1970 and 2011.

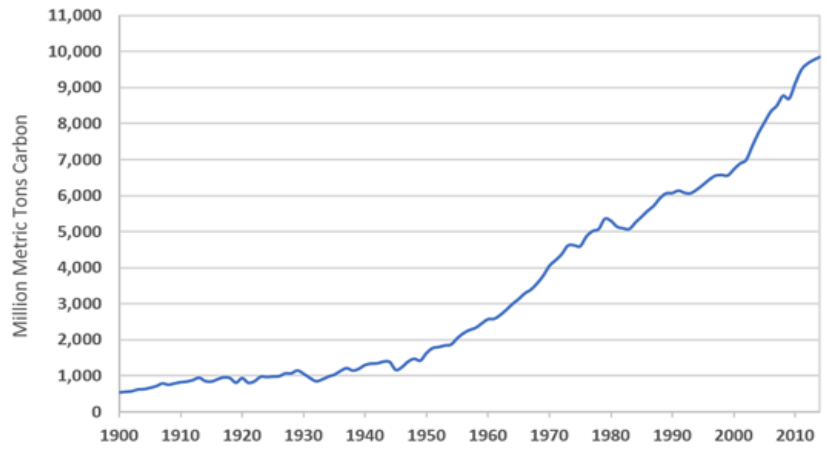

Figure 3: Global carbon emissions from fossil fuels, 1990 - 2014 Source: [9]

The trend at present may be moving downwards as recent data by the IEA[10] revealed that global energy-related $\mathrm{CO} 2$ emissions flattened in 2019 at around 33 gigatonnes (Gt), following two years of increases. The assertion was that, this resulted mainly from a sharp decline in $\mathrm{CO} 2$ emissions from the power sector in advanced economies and to the expanding role of renewable sources (mainly wind and solar PV), fuel switching from coal to natural gas, and higher nuclear power output. The IEA's analysis also revealed that Global $\mathrm{CO} 2$ emissions from coal use declined by almost 200 million tonnes (Mt), or 1.3\%, from 2018 levels, offsetting increases in emissions from oil and natural gas. A decline of about 3.2\% representing over $370 \mathrm{Mt}$ emissions decline was recorded for advanced economies and the power sector was responsible for $85 \%$ of the drop. It was further noted that milder weather in many large economies compared with 2018 had an important effect on the trends, reducing emissions by around 150 Mt. Weaker global economic growth also played a role, moderating the increase in emissions in major emerging economies such as India. The emissions trends for 2019 suggest the power sector has contributed significantly to the reduction and this may be attributed to ongoing global clean energy transitions.

The lack of clean, safe, affordable and environmentally friendly energy a paradigm coined as energy poverty is in part responsible for deforestation and carbon emissions (see [11, 12] for energy poverty definitions). According to the world environment organisation (WEO), it is estimated that about 1.3 billion people in the World in 2012 did not have access to electricity and 2.6 billion did not have access to clean cooking energies [13]. The 2.6 billion people with no access to electricity used biomass to meet their primary energy needs. 95\% of those with no access to electricity live in Asia and sub-Saharan Africa. In terms of numbers Asia due to its population size has more people with no access, but the level of access is typically lower in sub-Saharan Africa. There are also areas without access to these services elsewhere, e.g. Latin America, the Middle East and North Africa. Furthermore, everywhere else (especially in developed countries) access is almost universal, except in remote, rural areas [14].

In 2017, for the first time, the number of people without access to electricity dipped below 1 billion, but trends on energy access likewise fall short of global goals [1]. At least $80 \%$ of the world population has access to electricity with most access being recorded in developed countries where the main challenge is affordability. Developing countries have the least access and it 
remains the major challenge. As a global goal energy is to be affordable, clean and safe for all accessing it and the opposite of this is a dimension called energy poverty. Energy poverty can be described as "Lack of equitable access and safe utilization of energy, especially adequate, affordable, high quality, environment-friendly energy" [12]. Since the early 2000s, the developing countries have seen a steady change in access to clean cooking energy and access to electricity in general.

The IEA [15] gives a depiction of two scenarios (concerning the proportion of the population with access to electricity and clean fuels for cooking), the historical and ideal future of sustainable development goal 7 under Agenda 2030. It shows access to electricity and clean fuels for cooking, whereas the Middle East, Latin America, North Africa and developing Asia have had tremendous acceleration in improving access from the year 2000 to 2020 sub-Saharan Africa lags significantly and requires $60 \%$ change to meet the 2030 target. Similar sentiments can be attributed to cooking fuels although their 2030 attainment requires more effort. Sub Saharan Africa under which Zambia can be categorised has seen a leap from $10 \%$ to about $20 \%$ access to clean cooking and access to electricity from $20 \%$ to slightly above $40 \%$. Energy access occupies a central position at the intersection of global energy, environment, and development policy, in the wake of discussions on the Sustainable Development Goals (SDGs) defined by the United Nations (2015): SDG No. 7 requires "ensuring access to affordable, reliable, sustainable and modern energy for all". Similar to the other SDGs, energy access is defined both in terms of targets (access, rising share of renewables, energy efficiency, etc.) and indicators [16].

Zambia's energy is mainly comprised of $7 \%$ crude oil, $3 \%$ refined oil products, $1 \%$ coal, $11 \%$ hydro and $78 \%$ biofuels and waste [17]. The oils have been imported products that are not entirely consumed by households, it is coal and hydropower that is consumed by households and others as electricity including biofuels and waste. Hydroelectric power has seen a reduction in generation in the recent past owing to climate change whereas biofuels and waste have been on the increase.

Energy-related carbon emissions in Zambia are mainly linked to biofuel use and extensive agriculture. Zambia carbon (Co2) emissions have been on a rise, macrotrends.net [2] using World Bank data reveals an upward trend from 2010 to 2016.

Electricity access has been staggering, statistics from USAID indicate that currently national access to electricity averages at $31 \%$ with $67 \%$ of the urban and $4 \%$ of the rural population having access to power and currently households without power are about 7.2 million[18]. Access to modern energy is a central pillar of efforts to reduce poverty and support economic growth in sub-Saharan Africa [7]. The IEA defines a household as having energy access when it has reliable and affordable access to both clean cooking facilities and electricity, which is enough to supply a basic bundle of energy services initially, and with the level of service capable of growing over time [19]. This basic bundle of electricity services should encompass, at a minimum, several light bulbs, phone charging, a radio and potentially a fan or television. Access to clean cooking amenities means access to (and primary use of) modern fuels and technologies, including natural gas, liquefied petroleum gas (LPG), electricity, bioethanol, and biogas, or improved biomass cookstoves which, compared with basic biomass cookstoves and three-stone fires traditionally used in some developing countries deliver significant improvements. This definition of energy access serves as a benchmark to measure progress towards Sustainable Development Goal (SDG) 7.1 and as a benchmark for our forward-looking analysis [15].

Zambia demand for energy has been rising due to robust GDP growth of more than $6 \%$ per annum for the past decade in the country, specifically in the mining, manufacturing and agriculture sectors. According to the Zambia Development Agency (ZDA) [20], the demand for electricity in the country has been growing at an average of about 3\%, or between 150 and 200 MW, annually. However, there has not been any major addition to the country's generation capacity in the last 20-30 years despite a growing demand for power over the years and a rapid population increase. The CSO 2013 population and demographics projection report indicates that at the time of reporting the country's total population is anticipated to grow from 13.7 million in 2011 to 17.9 million in 2020 and 26.9 million by 2035 . The population in rural areas is expected to grow from 8.2 million in 2011 to 10.1 million in 2020 and 14.5 million by 2035 , while the population in urban areas is expected to grow from 5.6 million in 2011 to 7.8 million in 2020 and 12.4 million by 2035 (see [21]).

Also worth noting is the aspect of Southern Africa Power Pool (SAPP) that subtracts immensely from the country's capacity to meet growing demand. According to the SAPP [22] the pool consists of 12 countries with 280 Million people, its average electricity growth rate $2.5 \%$ p.a. and the energy consumption 400TWh/year. The pool, as at the end of January 2017 had capacity of 46,522 MW against a peak demand plus reserve of $53,036 \mathrm{MW}$ giving a shortfall of 6,514 MW. The annual electricity consumption reaches 50,000 MW per year, with an installed capacity of $55,000 \mathrm{MW}$. The annual growth rate of overall electric power consumption in the SAPP averages $5 \%$ per annum [20, 22].

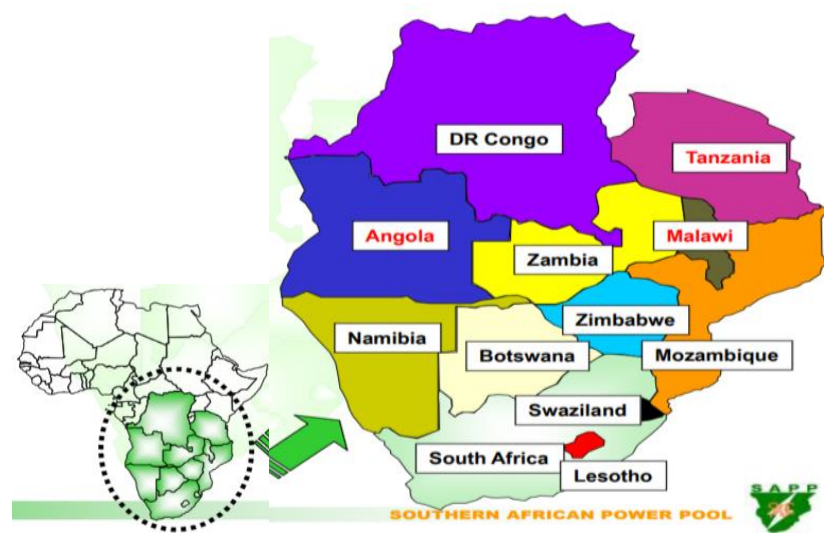

Figure 4: Southern African Power Pool

Source: [22]

Power pooling is about linking utility electricity production by facilitating the dispatch of excess capacity from one system to another. Thus the output from different power plants is pooled, scheduled according to increasing marginal cost, and dispatched on merit to meet demand. Some envisages benefits include: i) Increased security and reliability of supply (Provision of emergency support, Sharing spinning reserve capacity, and 
Balancing generation mix i.e. $74 \%$ coal, $20 \%$ hydro, $4 \%$ nuclear, $2 \%$ gas/diesel) ii) Improved sector investment environment ( Aggregation of individual power markets, Improved access to creditworthy and Diversification) iii) Reduced operating costs (Balancing non-coincidental peak-loads and Optimization of generation resources) and iv) Reduced \& deferred investment costs (Advantage of economies of scale, Reduced total reserve requirements (SAPP has managed from $20 \%$ to $10 \%$ ) and Postponed investments in new peak power capacity). This aspect of pooling is managed through various agreements such as bilateral contracts and others. Zambia features as an operating member (OP) as Zesco, Independent Transmission Company (ITC) as Copperbelt Energy Corporation and Independent Power Producer (IPP) as Lunsemfwa Hydro Power Authority. This entails its contributions are enormous seen that its major electricity participants are affiliated to the pool.

This study is relevant for the evaluation of the current energy structure, its characteristics and shortfalls, and the relationship between energy consumption and related carbon emissions. The rationale is to bring to readers, policy, and decision-makers with a view of Zambia's energy consumption and related emissions with optimism that the information provided could be a reference for sound energy planning, production and consumption to ensure sustainable energy for all. Review of various literature has shown a clear correlation between unsustainable energy practices and carbon emissions, Zambia would be no exception provided the low electricity access rate and affordability. These two aspects are key contributors to and bear an explicit relationship with emissions.

\section{ELECTRICITY STRUCTURE, ELECTRICITY GENERATION, CONSUMPTION AND CHARACTERISTICS}

\subsection{National energy structure}

As mentioned earlier, Zambia's energy is mainly comprised of 7\% crude oil, $3 \%$ refined oil products, $1 \%$ coal, $11 \%$ hydro and $78 \%$ biofuels and waste. Nationally, bioenergy contributes over $70 \%$ to total energy consumption. Households account for about $88 \%$ of wood fuel consumption out of which $60.9 \%$ of households use firewood for cooking and $24.3 \%$ used charcoal, Rural areas account for $87.7 \%$ of firewood use for cooking and $9.5 \%$ charcoal use[17]. Whereas, from the installed capacity of hydropower about 2878 MW of which $83 \%$ is hydro and non-hydro (Coal, Heavy Fuel Oil, others) at $405 \mathrm{MW}$. In terms of consumption, the mining sector accounts for over $50 \%$ of the generated electricity and $30 \%$ by the housing sector and the other is exported. This is according to the Ministry of Energy data.

There are five main electricity generation companies in Zambia, namely the state-owned Zambia Electricity Supply Corporation (ZESCO) Limited; Copperbelt Energy Corporation (CEC); NorthWestern Energy Corporation (NWEC); Lunsemfwa Hydro Power Company (LHPC); Zengamina Hydropower Company and Maamba Collieries Limited. Currently, parastatal ZESCO is the largest electricity company in the country, running and operating power stations, transmission lines, and distribution networks and is the only utility-scale off-taker of independent power producers
(IPPs). Zambia's installed capacity stands at 2,347 Megawatts (MW). The primary hydropower stations include Kariba North Bank Power Station, Kafue Gorge Power Station, Victoria Falls Power Station and, Itezhi Tezhi Hydro Power Station. There is one coal-fired plant, Maamba Collieries, commissioned in late 2016 and is currently generating $240 \mathrm{MW}$ of power for ZESCO. Demand for power in the economy has grown rapidly in recent years and continues to grow, refer to https://www.zambiainvest.com/energy.

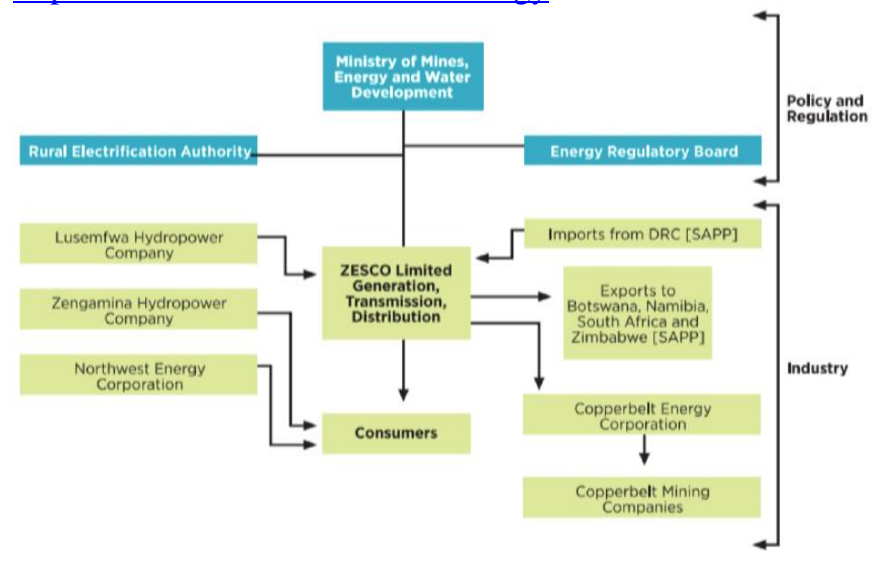

Figure 5: Zambia's power sector players

Source: Singh et al, 2013 in [23]

Its installed capacity is about $2878 \mathrm{MW}$ of which $83 \%$ is hydro and non-hydro (Coal, Heavy Fuel Oil, others) at $405 \mathrm{MW}$. In terms of consumption, the mining sector accounts for over $50 \%$ of the generated electricity and $30 \%$ by the housing sector and the other is exported [17].

\subsubsection{Beneficiaries of grid electricity}

The main sectors of the economy that benefit from national grid electricity include; mining, households, commerce and industry, services and agriculture and industry.

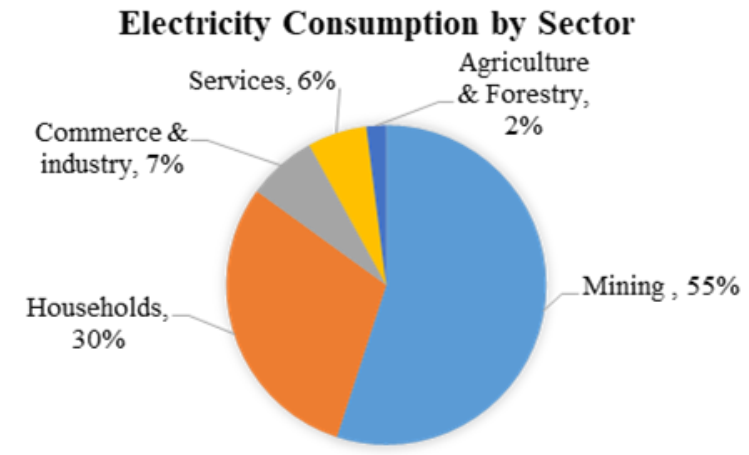

Figure 6: Electricity consumption by sector Source: [24]

Mining at 55\% derives more electricity service benefits because first and foremost it is the backbone of Zambia's economy. It has the highest contribution to the Gross Domestic Product (GDP). Commerce and industry and agriculture and forestry which have in recent years become active economic sectors put together with services do not consume less than the households. And despite the 
households having the second highest value of consumption, only $4 \%$ benefits rural populations and the rest urban populations.

We can say that the low consumption rate by the economic sectors other than mining and households depicts a weak relationship between growth in the energy sector and other sectors.

\subsubsection{Choice of energy options: comparison between rural and urban areas}

According to the UNDP [25] globally, 1.4 billion people don't have access to electricity and about three billion people rely on traditional use of firewood, charcoal, agricultural residues or coal for cooking. The various forms of bioenergy differ in terms of sustainability. Bioenergy feedstocks include different products and by-products from the agriculture, forestry and waste sectors (e.g. wood, charcoal, sugarcane, palm oil, animal waste) and there are many ways to use them to produce energy (heat, electricity and fuels). In Africa, as well as developing Asia, solid biomass remains the largest source of energy used by households (in energy-equivalent terms) and is often traditionally burned as fuel in inefficient and polluting cookstoves, using very basic technologies often with no chimney or one that operates poorly. This so-called "traditional use" of solid biomass is not sustainable and is associated with a range of damaging impacts on health and well-being. The volumes concerned are generally excluded when presenting shares of energy from renewable sources. This depicts a scenario of limited energy options for rural areas where electricity is a scarce energy source. Figure 5 below shows a typical composition of rural energy options.

\section{Typical Zambian rural area energy structure}

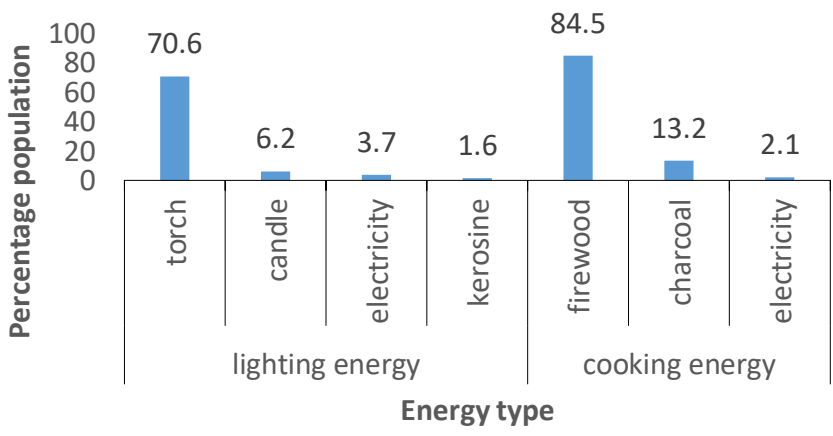

Figure 7: Percentage distribution of households by main source of energy for lighting and cooking in rural, Zambia.

Source: formulated based Living Conditions Monitoring Survey 2015 data $([26])$

Electricity is a common energy feature in developed countries and most urban areas of developing countries. The IEA [7] indicates that more than two-thirds of people without access to electricity in the world today live in sub-Saharan Africa. North Africa reached almost universal access to electricity by 2018, but the electrification rate in sub-Saharan Africa was $45 \%$ in that year. Electrification levels in sub-Saharan Africa remain very low compared to the levels in other developing parts of the world, most notably the $94 \%$ rate reached on average across developing countries in Asia. Zambia exists as one of the African countries with an extremely low electrification rate, its electricity is mainly concentrated along the line of rail which constitutes urban centers.

The lack of electricity as noted by IEA often obliges households, small businesses and community services that can afford it to use inefficient, polluting and expensive alternative solutions for essential services. It further stresses a challenge that the sub-Saharan region faces by highlighting the trends in population and electrification; "Despite the comparatively low access rate, sub-Saharan Africa has made progress with the pace of electrification accelerating over the past five years. The number of people gaining access to electricity for the first time more than doubled from 9 million a year between 2000 and 2013 to more than 20 million a year between 2014 and 2018, outpacing population growth for the first time. As a result, the number of people without access to electricity in sub-Saharan Africa peaked at 610 million in 2013, before slowly declining to around 595 million in 2018. The region now faces a dual challenge: how to provide access to the 600 million currently deprived while at the same time reaching the millions born every year in areas without access to electricity".

\subsubsection{Characteristics of Zambia's electricity}

Zambia's electricity is characterised by the following:

\subsubsection{Hydroelectric power predominant}

According to the Ministry of energy [7], Zambia has vast water resources. It contains $40 \%$ of the water resources in the Southern African Development Community (SADC), in terms of electricity generation there is about 6,000 MW unexploited hydropower potential, while only about 2,259 MW (37\%) has been developed. In addition to water reserves, Zambia has abundant renewable and non-renewable energy resources, including industrial minerals such as coal, agricultural land to support bio-fuels, ample forest for biomass, abundant wind for wind energy, long and intense hours of annual sunlight to support solar energy generation.

\subsubsection{Monopolised}

Zesco Limited was formed in 1970 after the Zambia Electricity Supply Act was passed in Parliament. This Act brought together the electricity undertakings that were previously managed by the local authorities. The Corporation traces its origins to 1906 when a small thermal station was installed in Livingstone to serve a small section of the town. In 1994, the name of Zambia Electricity Supply Corporation Limited was changed to Zesco Limited. This was to reflect the government's recommitment as a sole shareholder to providing a high quality of customer service see, [27].

Since its inception, Zesco has remained a dominant force in the energy sector until the introduction of IPPs. The IPPs except zengamina limited that directly services consumers in Ikeleng'i district the others feed into the national grid with Zesco as an offtaker, see figure 3. This reinforces Zesco's monopoly and blinds it 
to developing its infrastructure meant to enhance its service delivery.

\subsubsection{Unsubsidised}

Zambia for a long time had some of the lowest tariffs (non-cost reflective tariffs) in Africa, however, this has not translated into meaningful accessibility and affordability. The low tariff is a form of government subsidy. Cheelo [28], states that for a long time the Zambian Government ran a number of consumption and production subsidy programmes. These programmes came under considerable strain in 2015 when Zambia experienced a significant economic downturn. In that year, the real Gross Domestic Product (GDP) growth rate fell to $2.9 \%$, from an impressive $7.7 \%$ over the ten years before (2005-2014). By the time the 2015 downturn had fully set in, the country was running a budget deficit of nearly $10 \%$ of GDP and had raked up a public debt stock of over $50 \%$ of GDP. Chaurey et. al., [29] states that two seemingly irreconcilable situations dominate the power sector scene in developing countries like India: the ill financial health of state-run power utilities and the existence of a vast unserved poor population with low paying capacity. Thus, while power sector reforms seek to recover losses and introduce competition in the sector, government-administered subsidies for rural electrification are still recognized as essential for increasing access to the poor. Subsidy removal by Zambian government although not explicitly stated took effect in 2016 following the pronouncement by the energy regulation board that based on the policy decision of 2014, to remove fuel subsidies, and in line with the then current policy direction to migrate to cost- reflective pricing of energy services and products, the ERB revised the pump price of petroleum products. See [28].

\subsubsection{Urban area dominant}

The presence of the national grid is mainly concentrated along the line of rail which is characterised by urban areas. These are areas according to Borruso [30] with existence of the CBD and other functional areas (or sectors) surrounding the city centre. These areas have social services and facilities that may be considered as necessary for meeting basic human needs such as good housing infrastructure, social protection (police stations), health (hospitals), education (schools), employment (industry), governance (administrative offices) good roads, and banking and so on. In these areas electricity is a means for development and is therefore ably provided, rural areas in most cases lack the necessary infrastructure and services to attract electricity presence. And as noted by Kirubi [31] access to electricity, in conjunction with complementary infrastructure such as markets, roads, and communications, can contribute to increased productivity in two key economic arenas of rural livelihoods: small and microenterprises (SMEs) and agriculture. However, one factor is the distance at which they lie from the main grid which makes it a costly adventure to connect to the grid. Recent interest in rural electrification has emphasised the importance of linking its development with productive uses for energy and poverty reduction. This has been viewed as necessary to increase the pace of rural electrification and reduce its concentration on a relatively small number of developing countries. Despite this emphasis, progress in electrifying remote rural areas has been slow. In part, this has been attributed to the emphasis on cost recovery and a reliance on the private sector to deliver electricity widely [32]. On the other hand, the sparseness of the communities within rural areas makes it even more difficult to extend the service.

\subsubsection{Lack of an energy efficiency policy}

Having an energy efficiency policy is imperative at any societal level. Implementing energy efficiency policies to address market and behavioral failures can improve efficiency both in economy and energy use [33]. The existence of energy efficiency standards and labeling for household appliances and buildings play an important role in providing information and promoting energy efficiency to consumers and oblige producers to energyefficient designs. A country without energy efficiency standards or certification system does not promote energy efficiency from the policy point of view and therefore deteriorate the existence of energy poverty, while a country with mandatory efficiency labeling and minimal efficiency requirements for new appliances and buildings provides information for consumers and promotes efficient products and consequently reduces energy consumption by improving efficiency in the building structure and inventory of household appliances[12, 34]. Some national policies and laws that exist in other countries are to do with the most used and energy-consuming household appliances (fridges, freezers, washing machines, dishwashers, tumble dryers, electric stoves and ovens, televisions, air conditioners, lamps and space heaters) and residential buildings according to [12].

\subsubsection{Electricity generation and consumption per capita}

\subsubsection{Electricity access rate}

As noted in the first chapter of the paper, Zambia's electricity access rate stands at almost 40 percent of the population. And of the 40 percent urban and rural area access represented at $67 \%$ and $4 \%$ respectively bear an agonising huge difference between the two.

Zambia Electricity Access 1990-2017

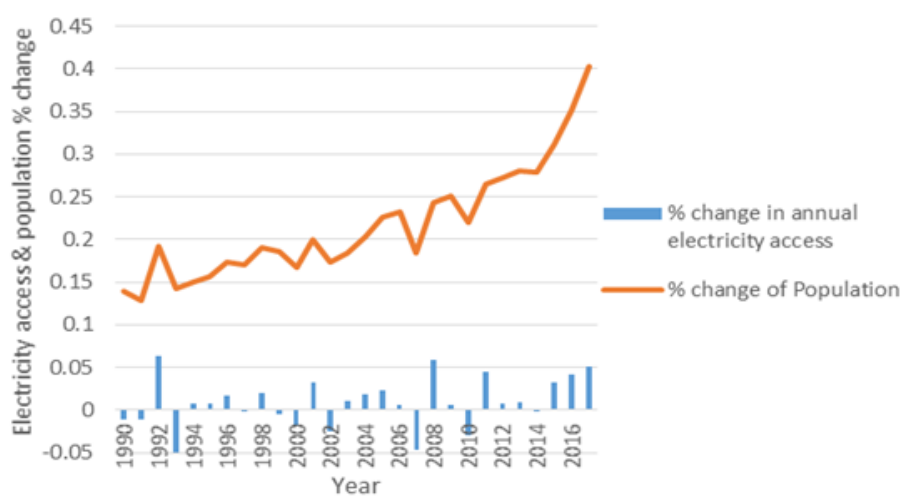

Figure 8: Zambia Electricity Access 1990 - 2017

Zambia's access rate as shown in figure 4 has not been an all positive increase trend but also had depressions. Notable 
major depressions occurred in 1993 and 2007 where values access rate dropped to $-0.05 \%$. Upward trends are featured noted in 1992 which so a sharp increase to at least +0.05 before the following year's similar opposite trend. Generally, we can say that from 1990 to 2017 access had increased to about $40 \%$ of the population.

\subsubsection{Electricity consumption per capita}

Despite access not being remarkable, electricity consumption per capita has been on a steady increase.

\section{Electricity Consumption per capita}

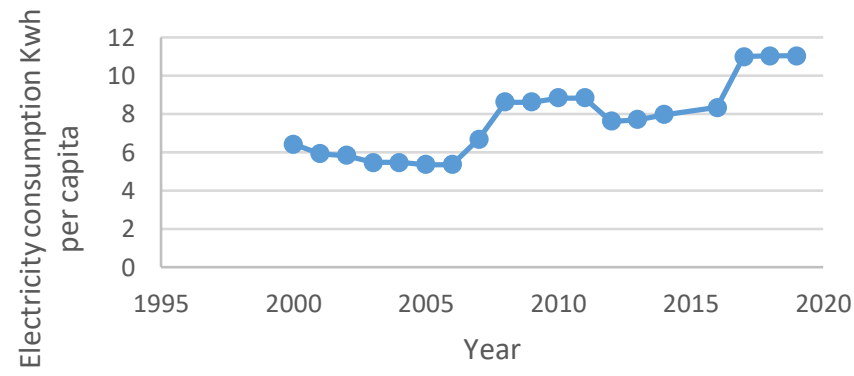

Figure 9: Electricity Consumption per capita 2000 to 2019 Source: [35]

Between 2000 and 2007 there was a downward trend in the consumption of electricity from at least 6 to almost 5 billion $\mathrm{kWh}$, this was overturned about 2009 with a sharp increase to 8 billion Kwh. Another decline was recorded about 2012 and about 2016 a shift upwards and a steady trend. However, a close look at the trend shows a downward trend from 2017 to 2019.

The year 2019 had been a difficult period for Zambia in terms of electricity consumption and this raised abnormally the service interruption duration. The national electricity service provider had to ration electricity among its beneficiaries and households were at the receiving end of the lowest and erratic supply.

\subsection{Woes of predominant single energy structure}

As stated earlier, 2019 was a year of extreme electricity service interruption. During the period of July and through to the year 2020, each day has been marred by not less than 8 hours of service interruption. The relevant authorities attributed this awkward phenomenon to climate change which is thought to be reducing water levels in the Kariba dam required to generate electricity.

\subsubsection{Widening electricity access gap}

The experience of power deficit continues to wedge the gap between the electricity 'have and have not's' population. As a result of deficit, efforts are mainly directed at improving supply to the haves. The haves who have suffered major service interruptions as noted in 2.1.4.2 reduced their consumption significantly as on most occasions electricity was available at awkward hours (late night) when they could not consume it effectively. It is therefore clear that during such times the electricity need of the 'have not's' could not be well prioritised which implicitly tells us that the gap has been widening under such conditions

\subsubsection{Reduced affordability}

Following the severe energy challenges that plagued the country, energy prices ranging from fuel pump prices and electricity tariffs have been on the rise. In a space of two (2) the energy regulation board approved applications from Zesco for upward change in electricity tariffs. Between 2017 and 2019 tariffs were increased by $75 \%$ and $200 \%$ respectively. The affordability reduces in light of a steady low growth gross domestic product, the low economic growth may not sustain the tariff increases for most of the population, see $[36,37]$ for statistical details.

\subsubsection{Increased gender inequality issues}

As noted by the WHO [38] even if now not fatal, the impact of respiratory illnesses reduces the human capital of household users as a consequence of ignored labour days and/ or missed schooling. This is especially the case amongst women and youth who are disproportionately affected by using indoor air pollution seeing that they are commonly responsible for domestic obligations. Lack of electricity results in inequality which spurs from household to other external levels where an opportunity level playing ground cannot be established.

\subsection{Potential social and economic risks of electricity supply insecurity}

Secure electricity may be considered as a safeguard of various factors including social and economic factors. In other words, it breeds potential social and economic factors. According to the European Commission as noted in Pedro \& Luis [39] security of supply is considered as an important objective of energy policy in many countries around the world. Together with efficiency and sustainability. Thus, any sound energy policy would have security of energy supply as one of its main pillars. The consequences of power outages as noted by Pedro \& Luis [39] are particularly important for most societies, very dependent on the availability of electricity, and may generate large economic and social costs.

\subsubsection{Economic costs/risks}

Economic costs may be described as financial loss as a result of electricity supply interruption and these have strong inclination to business and production. These cost may be classified into direct and indirect costs/risks. Where the former may include loss of production, restart costs, equipment damage and raw material spoilage. And the latter may include loss of market share, reduced profit margins, the cost of income being postponed and redundancy.

\subsubsection{Social costs/risks}

Social costs may be described as both tangible and intangible welfare loss as a result of electricity supply interruption. These 
costs may include, reduced ability to meet basic needs, relationship loss, and loss of leisure time, health and safety risk and so on.

\section{CARBON EMISSIONS}

As noted in sections of this paper, carbon emissions are from various sources. In this section, we endeavour to delve into emissions from the most common energy type among majority Zambian households that is biofuels. Specifically, we highlight how the production and consumption of biofuels in the form of wood fuel and charcoal contribute to carbon emissions and the resultant adverse effect on electricity production.

\subsection{Zambia's carbon emission trends}

Over a period of 50 years (1960 - 2014) Zambia's carbon emissions (CO2) were averaged at 0.45 metric tons per capita. Notable upward trends were recorded been between 1960 and 1970 and between 2010 and 2014. During the years, 2011, 2012, 2013 and 2014 emissions amount records were 2,937.27, 3667.00, 3,956.69 and 4.503.08 tons respectively, see [17]. This translated into percentage changes of $9.13 \%, 24.84 \%, 7.9 \%$ and $13.81 \%$ from on preceding year to the other.

\section{Zambia's Carbon Emission Trend}

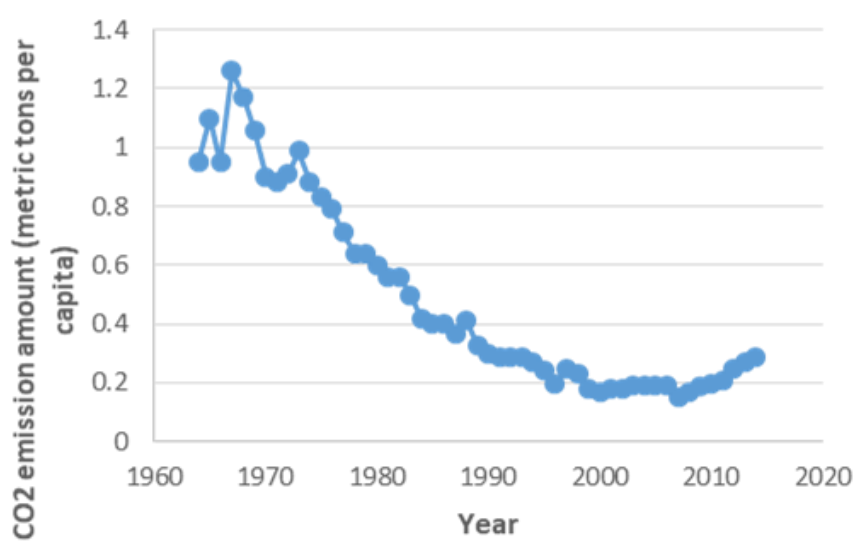

Figure 10: Zambia's Carbon Emission Trend 1960 to 2014

Source: Adapted from Index Mundi (refer to online citation, [40])

From the Index Mundi [40] data, it can be concluded that the amounts although still increasing, the increase is lesser than that of years before 2000. Between 1955 and 2000 Zambia's population increased gradually and reached 10.5 million in 2000, over the next decade it increased steadily to about 12.5 million in 2010, when last population census was conducted. A typical correlation analysis between emissions and population may suggest that population increase may have a corresponding result in emissions, which may be true in a year to year case analysis.
The overall depiction, in this case, may suggest a change in production and consumption practices or behaviours.

\subsection{Energy a major source of carbon emissions in Zambia}

Despite having cement manufacturing and coal and other industries which are globally noted as heavy carbon emitters on major Deforestation is an agent that contributes to carbon dioxide levels in the atmosphere. One major cause of deforestation is the ever-growing need for energy, especially among households. Indigenous trees are indiscriminately cut down for firewood and charcoal. These two sources of energy are available to both urban and rural areas but most common to the latter where electricity is often not a common feature. A large portion of stored carbon dioxide is released into the atmosphere when forests are cleared [41].

\subsubsection{Notable effects of deforestation for energy on hydroelectric power production}

Some deforestation occurring in Zambia is along major water bodies such as the Zambezi river basin. This river houses the Kariba dam (Kariba North, Kariba North Bank Extension) and Kafue Gorge upon which the nation grid relies. The river traversing through rural areas characterised by energy poverty experiences indiscriminate tree cutting along its river banks. A notable fact about the river is that the Zambezi River whose source is in Zambia flows through several countries before it empties into the Indian Ocean. Therefore the deforestation happening in Zambia could affect not only Zambia's rainfall but also that of the whole southern Africa region.

According to Banze [42], the Zambezi river basin is already experiencing drastic changes to its climate. In recent years the annual rainfall in the region decreased considerably and affected the annual flow levels. Over 128 million inhabitants that are part of the Zambezi River Basin are dependent on this river directly or indirectly as a source of food and water. In total, the countries along the Zambezi Basin have 2.17 million $\mathrm{km} 2$ of agricultural land, of which only $202,900 \mathrm{~km} 2$ is arable. But as a consequence of increased agricultural land, there is also an increased need for irrigation. The Intergovernmental Panel on Climate Change (IPCC) has categorized the Zambezi as the river basin exhibiting the "worst" potential effects of climate change among 11 major African basins. Over the next century, climate change is expected to increase this variability, and the vulnerability of the basin and its hydropower dams. The Zambezi River Basin has one of the most variable climates of any major river basin in the world and the runoff is highly sensitive to variations in climate, as small modifications in rainfall patterns produce large changes in runoff [43]

It is no strange science that rainfall reduction will ultimately result in water level reduction in the Kariba dam and consequently in electricity generation. The Zambezi River Authority (ZRA), the 
body responsible for the operation and maintenance of Kariba Dam Complex, investigation and development of new dam sites on the Zambezi River and analysing and disseminating hydrological and environmental information on the Zambezi River and Lake Kariba revealed that water allocation for power generation at Kariba North and South would be reduced by almost 600 megawatts, from the current $1476 \mathrm{MW}$ to 890MW. ZRA data on comparison of water intake across three (3) years of January months (when rainfall is expected to be normal) i.e. 2018 to 2020 had its highest water level at 50\% (only in January of 2019) against a normal of $100 \%$, see [44]. This not only reveals how adverse deforestation but also the downside of heavy reliance on one power source.

\section{ELECTRICITY REVIVAL PROSPECTS}

\subsection{Energy mix potential}

The country has several prospective energy avenues that could be considered crucial to reviving electricity service.

Table 1: Energy revival - Mini grid prospects/potential

\begin{tabular}{lll} 
Energy type & \multicolumn{1}{c}{ Capacity } & \multicolumn{1}{c}{ Status } \\
\hline Biomass & $500 \mathrm{MW}$ potential & $\begin{array}{l}\text { Biomass and Food Security Assessment } \\
\text { underway }\end{array}$ \\
Geothermal & $\begin{array}{l}80 \text { hot springs } \\
\text { available in Zambia }\end{array}$ & $\begin{array}{l}\text { 15MW to 90MW potential In Southern } \\
\text { Province (Lochniver Park) }\end{array}$ \\
Hydro & At least 1000MW & Under exploitation \\
Solar & $\begin{array}{l}\text { 6-8hrs/day, energy } \\
\text { output of }\end{array}$ & $\begin{array}{l}\text { Solar resource measurement completed } \\
\text { in 2017 }\end{array}$ \\
& $\begin{array}{l}\text { 5.5kwh/m2/day } \\
\text { Targeting on-grid 200 MW -Get Fit } \\
\text { (supported by REFIT Strategy) and } 600 \\
\text { MW -Scaling Solar Program }\end{array}$ \\
Wind & $\begin{array}{l}\text { Average speed } 7 \text {-8.2 } \\
\text { m/s at } 80 \text { meter } \\
\text { height }\end{array}$ & $\begin{array}{l}\text { 2 year wind resource assessment } \\
\text { completed in December 2018 }\end{array}$ \\
\hline
\end{tabular}

Source: Adapted from [24]

An energy mix is eminent especially with the introduction of IPPs. In terms of solar so far, two notable solar facilities that off-grid and servicing local communities are Muhanya solar Mpata hill which are private and state-run respectively. Hydropower generation potential is vast especially off grid based as a lot of river rapids that could support run off the river generation are located in rural and/or remote areas. One such remarkable IPP is Zengamina power limited which services the community of Ikeleng'i district. Refer to [45, 46]. Geothermal and wind energy although having been assessed have yet to be tapped into as useful energy resources. The same however cannot be said for biomass which is a common resource, especially in rural areas. Solid biomass can also be used for cooking and heating in more advanced, efficient and less polluting stoves. It can likewise be used as a fuel in combined heat and power plants or transformed into processed solid biomass (pellets), liquid biofuels or biogas. These are classified as modern uses of bioenergy.

Bioenergy has the potential to contribute to the decarbonisation of the power, heat and transport sectors, bringing wider benefits in terms of rural development and diversification of energy supply. There are some potential concerns regarding sustainability that have to be considered when planning to use biomass, however, including deforestation, loss of biodiversity, lifecycle greenhouse gas (GHG) emissions, land-use changes and air pollution linked to combustion. Environmental impacts are also severe, with dependency on biomass being associated with significant global deforestation in addition to increases in carbon release through combustion [7,47]. It is as a consequence essential that the attainable advantages of the use of bioenergy are balanced in opposition to the sustainability issues that are special to each bioenergy to provide chain application.

\subsection{Rural electrification programme}

The mother policy that supports the private sector participation in rural electrification is the rural electrification act of 2003. According to REA[48], through the Act the Rural Electrification Authority (REA) was established for purposes of i) mobilising, administering and managing the Rural Electrification Fund ii) financing project preparation studies for rural electrification and iii) recommending to government policies for the enhancement of rural electrification. In 2008 a Rural Electrification Master Plan (REMP) was formulated to plan for rural electrification and least cost technologies for rural electrification. The off-grid access rate through solar stands at $7.4 \%$, this includes the 60 Kilo-watt peak $(\mathrm{kWp})$ isolated solar mini-grid of Samfya District, Muhanya solar of Sinda district and/or others. The successes of the programme have included, 162 grid extension and 1,021solar projects between 2006 and 2017. During the period 2006 to 2015, a total of 3524 households comprising 2803 households at schools, 358 at rural health centers, 42 at the chiefs' palace and 321 at other public facilities were electrified. Further, 3853 private households comprising 813 households under the intensification programme in Chavuma, Mwansabombwe and Luangeni projects, 430 households under the Mpanta solar mini-grid project as well as 2610 households[49].

\subsection{Government reforms}

In its quest to increase enhance electricity access the government has put in place various incentives to support the growth of energy sector private players. This is especially to enhance their participation in rural areas where national grid presence is not available. Such measures have included; tax incentives on importation of energy-efficient and renewable energy equipment; promotion of improved biomass cookstoves and gas stoves; development and promotion of use of biofuels regulatory promotion of solar water heaters for households, SHS and Solar plants; Transmission and Distribution system rehabilitation to reduce losses and improve power quality and Time of use tariff (load shifting from peak to off-peak). Through the rural electrification authority (REA) programme (under 2008 Rural Electrification Master Plan) various technologies are being 
promoted for the rural areas including; Grid Extension, Mini hydro (from $200 \mathrm{~kW}$ to $10 \mathrm{MW}$ ) Development, Solar mini-grids, Solar Home System Installations, Biomass and recently Biogas and Wind. Other incentives under REA to accelerate rural electrification include, Capital subsidies in line with the REA Act, Project feasibility studies to identify sites which could be offloaded to the private developer, Public Private Partnership Models (for instance, IAEREP (Lunga, Chunga and Chishi) and Kasanjiku), Scaling-up Renewable Energy utilization and Electricity Service Access Project - ESAP (Smart Subsidy and Off-grid Loan facility) [48, 50]. The 2008 Statutory Instrument (SI No.32 and SI No. 33) on importation and exemption of some renewable energy and energy efficiency products from VAT and/or import tariffs is another measure. However, there have been concerns over the same as it is not easy to categorise the products and thus their exemption requirements are unclear.

\section{DISCUSSION}

In the recent past and currently, several challenges have plagued the Zambian economy and power deficit being one major challenge. Zesco the national electricity service provider was established in 1994 with Kariba dam as the main generation site, at this point, Zambia's population was about 9 million and the majority of the citizenry resided in the rural area. For almost half a century the generation system remained without upgrade or additional facilities. This overtime has overburdened not only generation but also transmission and distribution. The growth in population inevitably has an equal if not more resultant demand on energy. Besides the lack of strategic planning of electricity infrastructure, lack of access to electricity and its high cost have in part contributed to the large scale deforestation that plagues some parts of the country.

We could say that the extensive vegetation clearing has contributed to erratic changes in local climate which can be witnessed by persistent droughts and flooding in some parts of the country. Unique to this local climate change is the decrease in water levels especially in the Zambezi River which is the source of national power generation. Indeed as noted by the relevant authorities including the Zambezi river authority, water levels at the three large hydropower plants which make up three quarters of the nation's total generation (Kariba North, Kariba North Bank Extension and Kafue Gorge) and meet domestic consumption demand had reduced significantly. However, seen that this trended for at least three consecutive years, climate change can no longer hold as the main factor behind reduced generation and supply of electricity other factors may be at play as well. The inadequate electricity generation and subsequent supply insecurity has had great economic and social costs on the country. The countrywide power rationing from which on average, consumers experienced not less than 10 hours of electricity interruption resulted in equipment damage, loss of production and raw materials, reduced income, redundancy and crime among others.

Being part of the power pool despite being an economic venture meant for the country's financial benefit, it deprives to an extent the meeting of both existing and growing electricity demand. In other words, it exacerbates the wideness of the electricity gap between those that have and do not have access and between rural and urban areas. Realistically, one would not default on a power contract to avoid litigation thus would rather ration and tighten the power consumption belt internally.

The access rate has not been impressive so far after more than half a century of independence. Time and population increase have outpaced the development of electricity infrastructure. This occurrence time and again coupled with other factors are responsible for the low access rate. Between the year 2000 and 2010 national population increased only by 16 percent (2000 and 2010 population statistics were 10.53 and 12.53 million respectively see $[21,51]$ ) we could speculate that the meager increase was not enough to compel energy sector reform. The major depressions in the two decades were caused by drought and lack of planning. For instance, despite current and past problems with energy security due to its heavy reliance on hydropower generation declined 30 percent during a drought in 1991 refer to, [52, 53]. In 2011 the Central Statistics Office [21] projected the country's total population to grow from 13.7 million in 2011 to 17.9 million in 2020 at which point only $40 \%$ i.e. 7.2 million people have access. This entails a much wider gap between urban and rural areas in access sense. Rural areas as a result of unavailability and inadequacy of electricity infrastructure and other factors find themselves in the predicament of paying more to access or using alternatives. Charcoal and firewood continue to be the predominant cooking fuels in many rural and peri-urban households. Although this may be an issue of ordinary practices tending to endure even when cleaner alternatives are available in some cases. IPPs which are supposed to boost electricity service provision have had a slow growth rate. The rate of connectivity to the IPP grids signals challenges, for instance, Muhanya solar has had only about 60 and Zengamina 850 connected households since their existence. This is an unimpressive statistic that implies private sector support in rural electrification (and incentives) is insufficient.

Electricity subsidy removal and subsequent electricity price increase which has left most electricity users anguished is hoped to improve electricity access and affordability. The effect of the tariff system (government intervention to ensure that people could afford) has been the inability of Zesco to raise the much needed capital for new investments that would improve its generation and supply.

Generally, energy efficiency policy may cut across three primary types namely, financial incentives, product labels and energy efficiency standards. Financial incentives on the whole grant subsidies for households on efficient energy or electricity products, sometimes also make investments on energy-efficiency technologies. Product labels are many times used to furnish energy effectivity statistics for shoppers with the aid of disclosure of electricity use and display of power famous person on products, which are proved of value to minimize strength consumption, especially for these high consumption households. With efficiency policy, any saving on energy consumption would indeed go a long way.

\section{CONCLUSION}

The electricity challenges and related carbon emissions are as a result of dependence on a single energy source. This in itself could be sustaining but the lack of its maintenance and 
strategic planning has got the country to where it is today. The failure to plan ahead and invest in infrastructure accordingly has failed to meet both population and economic growth. The systems put in place to advance to access most especially in rural areas have achieved not as much. This, therefore, speaks volumes of why IPPs need more support from the government to reduce the gap between the energy haves and have not's. Energy efficiency can be identified as one aspect that helps to improve the difficulties posed by the inadequacies of the old hydropower infrastructure.

\section{IMPLICATIONS}

i. Energy poverty, especially among rural populations, is a contributing factor to $\mathrm{CO} 2$ emissions. Because of the lack of electricity access unsound means are used to bridge the gap between the energy need and best available alternative.

ii. Carbon emissions will soar high for as long as electricity access does not improve. Growing economic sectors will take up a lion's share in the name of development and downsizing the households' share.

iii. Rural electrification programme very critical is but so much an ineffective tool. Most rural electrification is done by the government through rural electrification authority this suggests that the playing field for IPPs is not well established for them to participate actively. Rural electrification to be effective requires adequate integration energy private sector players and allow them to tap benefits as per provision.

iv. The growth in IPPs seems stagnant with zengamina power limited and Muhanya solar being the most pronounced. Most upcoming energy players are strongly inclined to the provision of standalone solar home systems.

v. Policy reforms, especially on incentives, are key in the facilitation of the introduction of more IPPs in the generation of electricity

vi. Whereas the existence of incentives may be applauded their applicability have not yielded as much result as needed for improved accessibility especially in rural areas

vii. The energy mixing campaign has not yielded significant results especially at household level. it should instead be rolled out a vigorous energy mix campaign at all levels (from local to national level) with households being adequately sensitised on the importance of their role in the mix. Encourage them to adopt renewable energy technologies especially in cooking.

viii. Anthropogenic activities that seek to meet energy demand are a source of carbon emissions. Curbing energy-related anthropogenic drivers of deforestation and forest degradation through electrification key to emission reduction.

\section{CONFLICT OF INTEREST STATEMENT}

We declare that we have no financial and personal relationships with other people or organizations that can inappropriately influence our work, there is no professional or other personal interest of any nature or kind in any product, service and/or company that could be construed as influencing the position presented in, or the review of, the manuscript.

\section{REFERENCES}

[1] IEA, World Energy Outlook 2018.

[2] https://www.macrotrends.net/countries/ZMB/zambia/carbon-co2-emissions, Zambia Carbon (CO2) Emissions 1964-2019.

[3] Carbon Dioxide Information Analysis Center, E.S.D., Oak Ridge National Laboratory, Tennessee, United States.

[4] IPCC, Climate Change 2014: Mitigation of Climate Change . . 2014.

[5] EPA, Data, Global Greenhouse Gas Emissions. Public Data Release Report, Appendix B 2012: 2.

[6] FAO, Agriculture, Forestry and Other Land Use Emissions by Sources and Removals by Sinks. 2014

[7] IEA, Africa Energy Outlook, World Energy Outlook Special Report. 2019.

[8] https://www.worldatlas.com/articles/world-regions-with-thehighestdeforestation-triggered-by-unsustainable-charcoal-production.html, Available Online. Accessed on 17 January 2020.

[9] Boden, T.A., G. Marland, and R.J. Andres, Global, Regional, and National Fossil-Fuel CO2 Emissions, 1751-2006 (published 2009). 2009, Environmental System Science Data Infrastructure for a Virtual Ecosystem

[10] IEA, Global CO2 emissions in 2019. 2019.

[11] Reddy, A., Energy and social issues. In: World Energy Council and UNEP, editors. Energy and the challenge of sustainability, 2000.

[12] Bonatz, N., et al., A comparative study of the interlinkages between energy poverty and low carbon development in China and Germany by developing an energy poverty index. Energy and Buildings, 2019. 183: p. 817-831.

[13] WEO, 2014.

[14] González-Eguino, M., Energy poverty: An overview. Renewable and sustainable energy reviews, 2015. 47: p. 377-385.

[15] IEA, World Energy Outlook. 2018.

[16] Karplus, V.J. and C.V. Hirschhausen, "Electricity Access: An Introduction.". Economics of Energy \& Environmental Policy, 2019. 8(1).

[17] MoE, Beyond The Grid Fund For Africa (BGFA) Presentation on Bioenergy in Zambia, Current and Pipeline Initiatives. Bioenergy Workshop, 2019.

[18] USAID, Power Africa fact sheet 2018.

[19] IEA, 2019a.

[20] Zambia Development Agency, (Z.D.A)., n.d.

[21] Central Statistics Office, 2013. 2010 CENSUS OF POPULATION AND HOUSING : Population and Demographic Projections 2011 - 2035.

[22] Workshop, S.A.P.P.S.I., Meeting growing power demands through Southern African regional integration. $24-25$ April 2017

[23] Batidzirai, B., A. Moyo, and M. Kapembwa, Willingness to pay for improved electricity supply reliability in Zambia. 2018.

[24] Ministry of Energy, Policies Supporting Private Sector Participation in Rural Areas. 2019.

[25] UNDP, UNDP Fast Facts: Universal Energy Access (2022).

[26] Central Statistics Office, 2015 Living Conditions Monitoring Survey Key Findings. 2015.

[27] http://www.zesco.co.zm/aboutUs/briefHistory.

[28] Cheelo, C. and R. Haatongo-Masenke, "Blanket" Fuel and Electricity Subsidies Did Not Offer Much Benefit to Zambia's Poor. 2018(Working Paper No. 32).

[29] Chaurey, A., M. Ranganathan, and P. Mohanty, Electricity access for geographically disadvantaged rural communities - technology and policy insights. Energy policy, 2004. 32(15): p. 1693-1705.

[30] Borruso, G., Network density and the delimitation of urban areas. Transactions in GIS, 2003. 7(2): p. 177-191.

[31] Kirubi, C., et al., Community-based electric micro-grids can contribute to rural development: evidence from Kenya. World development, 2009. 37(7): p. $1208-1221$

[32] Cook, P., Infrastructure, rural electrification and development. Energy for Sustainable Development, 2011. 15(3): p. 304-313. 
[33] Gillingham, K. and K. Palmer, Bridging the Energy Efficiency Gap: Policy Insights from Economic Theory and Empirical Evidence. Review of Environmental Economics and Policy, 2014. 8(1): p. 18-38.

[34] Edouard Toulouse, J.K., das Market Watch-Konsortium, Anleitung zur Kontrolle der Energielabel und Ökodesign-Vorgaben für Verbraucher*innen, , Initiativen und NGOs, United Kingdom: . Energy Saving Trust 2016.

[35] CIA, World Fact book Available Online: https://www.indexmundi.com/g/g.aspx?c=za\&v=81

[36] ERB,http://www.erb.org.zm/downloads/eregulation/zescotariffs/erbApprov edTariffScheduleMay2017.pdf.

[37] Macrotrends, <href='https://www.macrotrends.net/countries/ZMB/zambia/ta riff-rates'>Zambia Tariff Rates 1993-2020</a〉. www.macrotrends.net. Retrieved 2020-01-22. 2020.

[38] WHO, Burden of Disease From Household Air Pollution for 2012,. World Health Organisation, Geneva, Switzerland, 2014.

[39] Linares, P. and L. Rey, The costs of electricity interruptions in Spain. Are we sending the right signals? Energy Policy, 2013. 61: p. 751-760.

[40] https://www.indexmundi.com/facts/zambia/indicator/EN.ATM.CO2E.PC.

[41] López, R. and G.I. Galinato, Deforestation and forest-induced carbon dioxide emissions in tropical countries: how do governance and trade openness affect the forest-income relationship? The Journal of Environment \& Development, 2005. 14(1): p. 73-100.

[42] Banze F, Guo J, and X. S., Variability and trends of rainfall, precipitation and discharges over zambezi river basin, southern africa: review. . Int J Hydro., 2018. 2(2): p. 137-140.

[43] Beilfuss, R., A Risky Climate for Southern African Hydro: Assessing Hydrological Risks And Consequences For Zambezi River Basin Dams. International Rivers (September), 2012: p. 1-5.

[44] Zambezi River Authority (ZRA), http://www.zambezira.org/hydrology/kariba-reservoir-data. 2020

[45] North West Zambia Development Trust, Zengamina Hydro Project: Alleviation of poverty and improved public health through sustainable development. 2013.

[46] INSIGHTS, G.I.M., Zambia: Solar PV and Hydro Mini-Grids Developer Guide. DEVELOPER GUIDE / MODEL BUSINESS CASE / CASE STUDY, 2019.
[47] Jürisoo, M., et al., Old habits die hard: Using the energy cultures framework to understand drivers of household-level energy transitions in urban Zambia. Energy Research \& Social Science, 2019. 53: p. 59-67.

[48] REA, Rural Electrification Authority's OFF-GRID INITIATIVES TO ACCELERATE RURAL ELECTRIFICATION IN ZAMBIA. Beyond the Grid Fund for Africa Workshop, 2019.

[49] REA, Rural Electrification Authority STATUS OF RURAL ELECTRIFICATION IN ZAMBIA. Lusaka Presentation by Mr. Geoffrey Musonda - Chief Executive Officer (CEO), 11thApril 2017.

[50] UNEP, DTU, and C2E2, Energy Efficiency Roadmap for Zambia Global Workshop on Accelerating Energy Efficiency Copenhagen, Denmark, 2015.

[51] CSO, Central Statistics Office SUMMARY REPORT 2000 CENSUS OF POPULATION AND HOUSING. 2003.

[52] Kozacek, C., Zambia Electricity Shortage Highlights Africa's Hydropower Shortfalls. Africa, Climate Change, Hydropower, Mining, Water News 2015.

[53] Zambia Position Paper on Electricity. 2009

[54] Young G. O., "Synthetic structure of industrial plastics (Book style with paper title and editor)," in Plastics, 2nd ed. vol. 3, J. Peters, Ed. New York: McGraw-Hill, 1964, pp. 15-64.

\section{AUTHORS}

First Author - Rejoice Mwamba, College of Environmental Science and Engineering, Tongji University, Shanghai, China. E-mail address: mwamba.rejoice@yahoo.com

Second Author - Ru Guo, Institute of Environmental Planning and Management, College of Environmental Science and Engineering, Tongji University, Shanghai,

China. E-mail address: ruguo@ tongji.edu.cn

Third Author - Simon Garang Kuch, College of Environmental Science and Engineering, Tongji University, Shanghai, China. E-mail address: bensonkuch@gmail.com

Corresponding Author-Ru Guo. E-mail address: ruguo@tongji.edu.cn Tel.: +8613816352977. 